\title{
The Importance of the Laboratory Quality Management System in the Academic Curriculum in Developing Appropriate Student Competences for Our Current Societal Needs ${ }^{+}$
}

\author{
Cecilia Arsene ${ }^{1,2, *}$, Simona Maria Cucu Man ${ }^{1}$ and Romeo Iulian Olariu 1,2 \\ 1 Faculty of Chemistry, “Alexandru Ioan Cuza” University of Iasi, 11 Carol I, 700506 Iasi, Romania; \\ sman@uaic.ro (S.M.C.M.); oromeo@uaic.ro (R.I.O.) \\ 2 Integrated Center of Environmental Science Studies in the North Eastern Region (CERNESIM), \\ “Alexandru Ioan Cuza" University of Iasi, 11 Carol I, 700506 Iasi, Romania \\ * Correspondence: carsene@uaic.ro \\ † Presented at the Virtual Eurachem Workshop 2020 - "Quality Assurance for Analytical Laboratories in the \\ University Curriculum", 14-15 July 2020; Available online: https://eurachem2020.ro/.
}

Published: 21 September 2020

\begin{abstract}
Laboratory quality management system is a concept of utmost importance for industry and other economic sectors. Nowadays, even for university laboratories it is possible to have accredited tests according to standard ISO/IEC 17025. This paper demonstrates a way of evaluating the potential of academic experts to integrate successfully the quality management systems of a chemical analysis laboratory in the teaching process. However, designing an appropriate academic curriculum responding to our current societal needs is still very challenging. In teaching and developing practical competences in analytical quality assurance, training offered to students in aspects related to the validation of an analytical method including performance characteristics such as selectivity and specificity, linear range, sensitivity, limit of detection, limit of quantification, ruggedness, accuracy, precision, etc., are primary steps in the process of a complete understanding of quality management system topics. This contribution presents a compilation of the most important current developments in a university chemical analysis laboratory with good results in developing theoretical and practical skills in analytical quality assurance for students, graduates and postgraduates alike. Teaching students with an interdisciplinary approach allows them to gain knowledge in making connections between disciplines and theories, between practical problems and accumulated knowledge, and between society's assumptions, expectations, and needs.
\end{abstract}

Keywords: quality management system; academic curricula; competences; societal needs; chemical analysis laboratory; analytical quality assurance

\section{Introduction}

Education plays a pivotal role in sharing and teaching fundamental values [1] and, nowadays, innovative education is seen as one of the most suitable tools that can be used to foster students' knowledge, innovation ability, creative spirits, and suitable practice skills to fulfill our current societal needs. Universities, assigned also as high-level educational institutions, supply appropriate frameworks for instilling and fostering students' competences related to essential knowledge, skills and attitudes, critical thinking and critical use of the available media support tools, and open-minded social attitudes. Extensive literature covers areas related to human capital and growth [2], but relatively little information refers to the economic impact of universities themselves [3]. In 
universities aimed at qualifying human resources and producing knowledge by an appropriate curriculum design, a dynamic and flexible interaction with other institutions and companies is of utmost importance in achieving the common task of responding in a suitable way to the demands of our current societal needs (Figure 1).

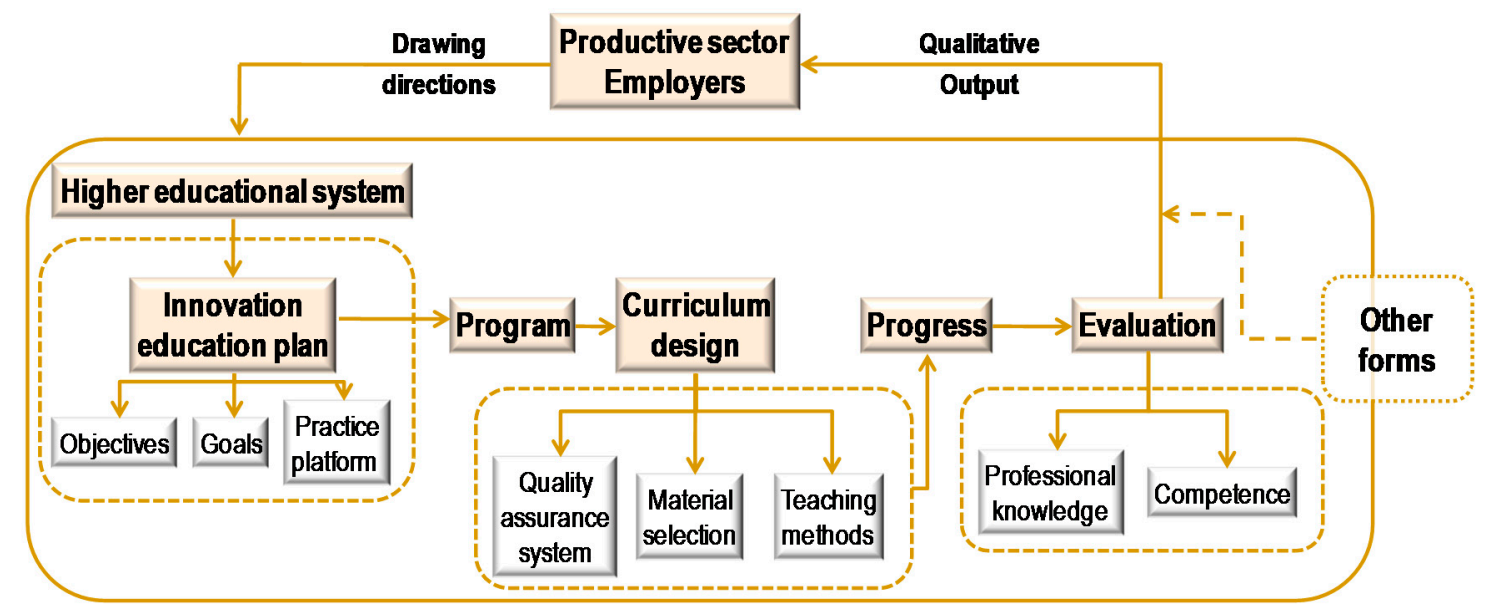

Figure 1. The relationship diagram between higher education system tasks and employers from various sectors.

Implementation in the academic curricula of disciplines related to the quality management system (QMS) concept might be of great help in fulfilling the objective of creating a closer relationship with private companies looking for quality. Training students in a wide range of fields to pursue interdisciplinary research is one of the most important objectives of a high-level educational institution $[4,5]$. The broad concept of QMS is an essential item to guarantee quality in all specific activities and processes undertaken not only in a general operational entity but also in higher educational units. Although advantageous in terms of increasing efficiency of operations and reduction in number of processes, implementation of a QMS in university laboratories is still a highly complex task [6,7]. In general, a QMS is well represented by concepts covering aspects related to: (i) collection of processes and functions aimed at continuous improvement of quality such as ensuring customer expectations and requirements to be met or exceeded, (ii) the framework of organized structures, methods, techniques, policies, procedures, processes, and resources implemented in a structure, and (iii) the methods by which each entity can ensure responsibilities, schedules, relationships, contracts, and compliance with the environmental, food, and product safety standards.

\section{ISO/IEC 17025 Relationship towards Innovative Academic Curricula}

Specific definitions given by the International Organization for Standardization (ISO) and the International Electrotechnical Commission (IEC) reveal that for a chemical analysis laboratory the QMS concept should be specifically referred to as a management system aimed to direct and control the lab activity with regard to quality, regardless of the economic sector activity which is addressed, i.e., industry, environment, human health issues, etc. In this context, the role of universities in the production of knowledge and training to create highly qualified professionals able to enter sectors centered on chemical analysis is of vital importance. The ISO/IEC 17025 standard is useful not only for conformity assessment bodies with the need to do testing, sampling or calibration but also to universities, research centers, governments, regulators, inspection bodies, and product certification organizations [8]. For chemical analysis laboratories, full understanding of ISO/IEC 17025 requirements currently enables these units to define best practices, increase responsibility, and ensure clarity and full disclosure of the most reliable results to all economic sectors where quality data are required. Nowadays, educational institutions are strongly encouraged to optimize their curriculum system by creating a variety of elective courses with a focus on practical courses 
understanding and practical cooperation platforms for an effective application of students' theoretical knowledge [9]. Moreover, results produced by university testing laboratories with implemented quality management system on ISO/IEC 17025 and accreditation, would always have a positive impact on research studies and academic content [10].

Integration of the quality management system elements as a whole in a laboratory centered on developing students' background skills and competences on quality assurance issues requires time and academic effort. It is already known that quality matters have always been an intrinsic component of any curriculum in analytical chemistry. Usually, in order to meet industry requirements related to compatible measurement systems, an appropriate and vigorous program of university education in analytical quality assurance $(\mathrm{QA})$ and quality control $(\mathrm{QC})$ issues is necessary in all universities [11]. While in research and chemical analysis laboratories the QA concept is seen as the tool helping in solving all problems concerning quality, through both its quality control and quality assessment components [12], quality control appears as a suitable tool mainly used to monitor the accomplishment of a test and to better describe a result [13]. It is, however, inferred that in routine chemical analysis laboratories the quality control is more important, while in research laboratories quality assessment is dominant [12]. Actually, for an analytical chemistry laboratory QA and QC issues are essential tools to ensure good comparability of data and results. Usually, in order to achieve these purposes, processes are monitored and performance problems are systematically solved [14].

In an academic curriculum where analytical chemistry disciplines might have the option to integrate elements of QA and QC concepts, items related to ISO/IEC 17025 should become important aspects to be introduced to students with interest in gaining experience specific for testing and/or calibration labs targeted in certification. ISO/IEC 17025 is actually the best option for training students for the quality standards governing testing in all chemical laboratories. In laboratories centered on chemical analysis and analytical chemistry, students become aware of the fact that achieving, maintaining, and improving accuracy and reliability of reported test results are major challenges for all laboratories involving chemical analysis of various products. Moreover, over the bachelor and master studies the students have the possibility to understand how challenging it is to provide reliable chemical data with a reduced level of inaccuracy to the community's needs, especially when speaking about medical, pharmaceutical, environmental, and resources sector agencies.

There is already general recognition of the fact that training in quality matters is important at all levels of education. Moreover, many quality concepts are actually standard parts of education in analytical chemistry [11]. Students trained in analytical chemistry disciplines gain knowledge on the importance of data and sample traceability toward internationally accepted standards. The academic curricula of the "Alexandru Ioan Cuza" University of Iasi offer master students the opportunity to be trained in educational challenges involved in performing transition from practice to the requirements of an internationally accepted system such as ISO/IEC 17025. Within the "Quality management in chemical analysis: ISO requirements" course (a course introduced in the academic curriculum of the university from 2010 until 2019) some of the most important components of the training strategies were related to formal aspects of quality systems corroborated with practical measures of good analytical practice for a better understanding of the role in maintaining the quality of a specific system (Figure 2).

Master students, within the "Quality management in chemical analysis: ISO requirements" course, were trained in almost every single aspect related to the validation of analytical methods including performance characteristics such as selectivity and specificity, linear range, sensitivity, limit of detection, limit of quantification, ruggedness, accuracy, precision, etc. With a syllabus addressed to master students, concepts as data intercomparison, identification of critical steps in multi-stages procedures, optimal sampling strategies and estimation of uncertainties of analytical results were efficiently taught within this course. Unfortunately, emphasis on the topics of interest had to be continuously adjusted depending on the students' interests. However, simulation of an accreditation process for testing laboratory units created by distinct groups of students was one of the best teaching and training instruments in this regard. Student feedback on the course syllabus revealed as the most important developed skills: (a) assimilation of indispensable information for 
analytical laboratory work, (b) understanding the importance of a transdisciplinary approach in quality control assurance, (c) increasing motivation for a continuous professional training, (d) laboratory activity validation of an analytical method, (e) data dissemination/communication, (f) improving of team work abilities, (g) highlighted skills of each team member, (h) distribution of activities to support students with lower theoretical and practical background, (i) undertaking and fulfilling a task, ( $\mathrm{j}$ ) asking for additional information in order to avoid misunderstanding of a job task or work procedure, (k) improving organizational public speaking skills, (l) learning new analytical techniques.

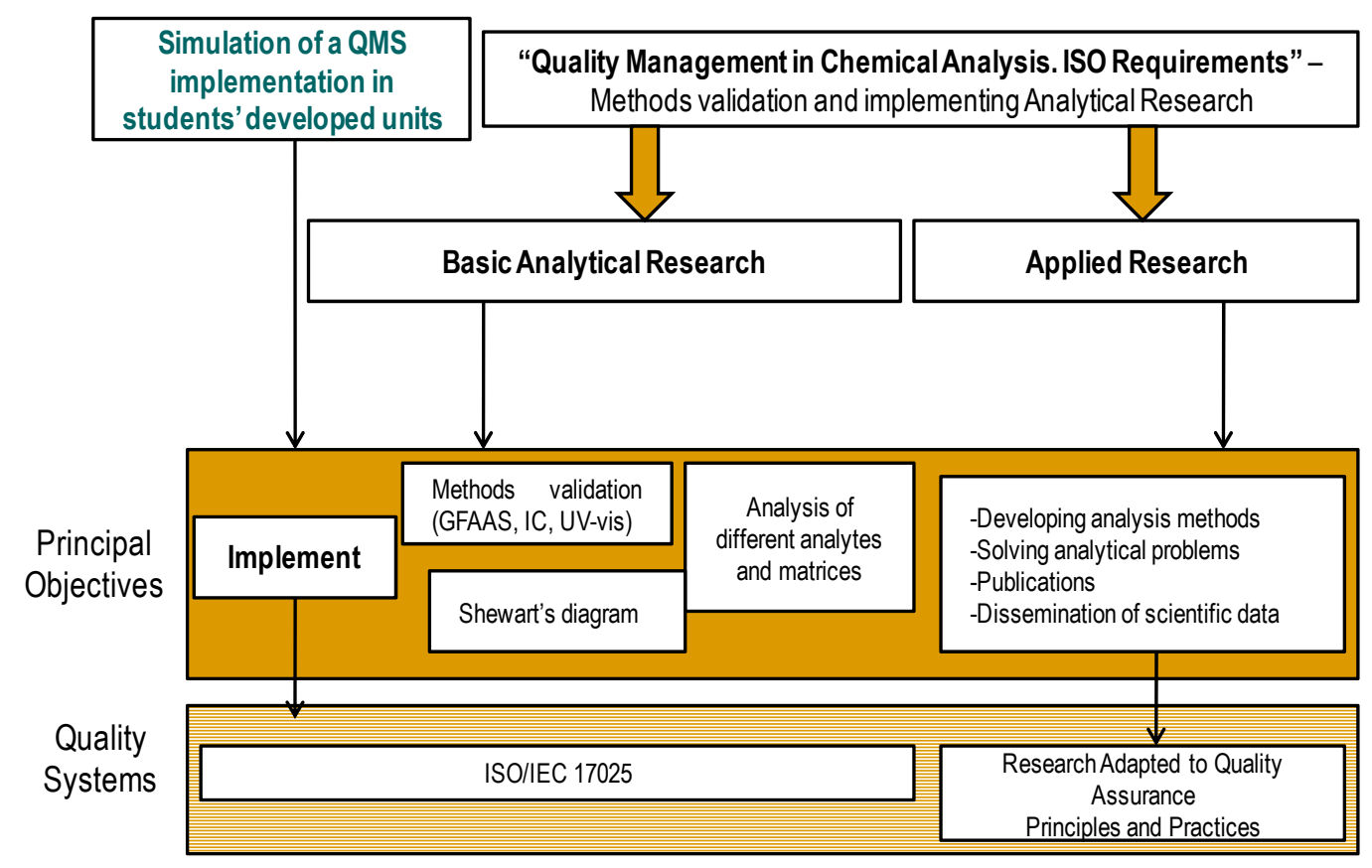

Figure 2. The strategy for practice within the "Quality management in chemical analysis: ISO requirements" course in the academic curriculum of the "Alexandru Ioan Cuza" University of Iasi.

It is, however, worth mentioning that addressing all the analytical quality assurance topics within a single course is very difficult to achieve. It is an activity which strongly depends on the students' interests and aims. With respect to this matter, success in the implementation process of the syllabus of education in analytical quality matters was ensured by teachers in analytical chemistry with appropriate aptitudes to teach about the meaning of the general requirements for the competence of testing and calibration laboratories. Professors in analytical chemistry, involved as key personnel in the implementation and accreditation process of a QMS in the Laboratory of Analytical Chemistry and Instrumental Analysis (LAICA) unit of the "Alexandru Ioan Cuza" University of Iasi, in full agreement with ISO/IEC 17025 requirements, have undertaken the challenge of the practical work in the syllabus of the "Quality management in chemical analysis: ISO requirements" course. Moreover, within this course students were trained clearly to understand the difference between accuracy and trueness, errors or confidence limits and uncertainty, and many other quality issues. Over the years, it was obvious that using the language of analytical quality assurance as internationally agreed upon, as a teaching method, was one of the most suitable routes helping an important number of Master of Science students in obtaining important positions within structures with an implemented QMS.

\section{Conclusions}

In the context of the analytical quality assurance issues, it is strongly believed that society should take advantage of the knowledge and expertise of academic staff. Moreover, universities with experts in analytical quality assurance might also take advantage of widening their offer 
through courses which can be offered both at the internal level (students) but also at the external level, with specific items of high interest not only for industry but also for government institutions.

In developing innovative education, universities should also take into account students' suggestions related to the quality concept future in the academic curricula by including at least an optional discipline during bachelor's degrees, with basics about quality, for students who intend to get a job in the field without a master's degree. Students also consider as quite important the role of inviting experts in laboratory accreditation or quality assurance and quality control fields. Moreover, upon their suggestion, creating an independent accredited course that can be accessed from outside the university by people who need to gain this type of knowledge, not just by students, might be of great impact. Clearly stated topics in a course on quality in chemical analysis, related to standard analysis methods, data accuracy, precision, trueness, uncertainty, error, traceability, use of certified reference materials, and statistics of calibration and of data validation, will make the issues of analytical quality assurance some of the most modern tools for our society.

Author Contributions: Conceptualization, C.A.; Resources, C.A., S.M.C.M., R.I.O.; Data curation, C.A., S.M.C.M., R.I.O.; Writing-original draft preparation, C.A.; Writing-review and editing, C.A., S.M.C.M., R.I.O.; Supervision, C.A. All authors have read and agreed to the published version of the manuscript.

Funding: This research received no external funding.

Acknowledgments: The authors thank Cornelia Amarandei and Alina Giorgiana Negru for their feedback related to the "Quality management in chemical analysis: ISO requirements" course, and also for their contribution to the editing of graphs.

Conflicts of Interest: The authors declare no conflict of interest.

\section{References}

1. European Commission. Education and Training, Monitor 2018; Publications Office of the European Union: Luxembourg, 2018; doi:10.2766/28521. Available online: https://op.europa.eu/en/publication-detail/-/publication/d576345f-e888-11e8-b690-01aa75ed71a1/language -en (accessed on 9 April 2020).

2. Valero, A.; Van Reenen, J. The economic impact of universities: Evidences from across the globe. Econ. Educ. Rev. 2019, 68, 53-67, doi:10.1016/j.econedurev.2018.09.001.

3. Bekkers, R.; Freitas, M.B. Analysing knowledge transfer channels between universities and industry: To what degree do sectors also matter? Res. Policy 2008, 37, 1837-1853, doi:10.1016/j.respol.2008.07.007.

4. Coskun, S.; Kayikci, Y.; Gencay, E. Adapting engineering education to industry 4.0 vision. Technologies 2019, 7, 10, doi:10.3390/technologies7010010.

5. Marbach-Ad, G.; Marr, J. Enhancing graduate students ability to conduct and communicate research through an interdisciplinasry lens. J. Microbiol. Biol. Educ. 2018, 19, 1-11, doi:10.1128/jmbe.v19i3.1592.

6. Dehouck, P.; Koeber, R.; Scaravelli, E.; Emons, H. The integration of quality management systems in testing laboratories: A practitioner's report. Accredit. Qual. Assur. 2019, 24, 151-156, doi:10.1007/s00769-018-1365-1.

7. Grochau, I.H.; Ferreira, C.A.; Ferreira, J.Z.; ten Caten, C.S. Implementation of a quality management system in university test laboratories: A brief review and new proposals. Accredit. Qual. Assur. 2010, 15, 681-689, doi:10.1007/s00769-010-0713-6.

8. ISO/IEC 17025 PUB100424, General Requirements for the Competence of Testing and Calibration Laboratories, Geneva, Switzerland. $2017 . \quad$ Available online: https://www.iso.org/publication/PUB100424.html (accessed on 9 April 2020).

9. Yu, Z.; Zhou, S.; Li, Y. An analysis of influencing factors of innovative education and development proposal. In Proceedings of the International Conference on Education Reform and Modern Management (ERMM 2014), Phuket, Thailand, 11-12 January 2014; Atlantis Press: Paris, France, 2014; pp. 57-61, doi:10.2991/ermm-14.2014.17.

10. Zapata-Garcia, D.; Llaurado, M.; Rauret, G. Experience of implementing ISO 17025 for the accreditation of a university testing laboratory. Accredit. Qual. Assur. 2007, 12, 317-322, doi:10.1007/s00769-007-0274-5.

11. Wegscheider, W. Standardization, quality control and education in analytical chemistry. Fresenius J. Anal. Chem. 1994, 349, 784-793, doi:10.1007/BF00323107. 
12. Prosek, M.; Golc-Wondra, A.; Krasnja, A. Quality assurance systems in research and routine analytical laboratories. Accredit. Qual. Assur. 2000, 5, 451-453, doi:10.1007/s007690000236.

13. Zaman, G.S. Introductory chapter: History and scope of quality control in laboratories. In Quality Control in Laboratory; Zaman, G.S., Ed.; IntechOpen: London, UK, 2018, doi:10.5772/intechopen.74593.

14. Rauf, M.A.; Hanan, A. Quality assurance considerations in chemical analysis. Qual. Assur. J. 2009, 12, 16-21, doi:10.1002/qaj.435.

(C) 2020 by the authors. Licensee MDPI, Basel, Switzerland. This article is an open access article distributed under the terms and conditions of the Creative Commons Attribution (CC BY) license (http://creativecommons.org/licenses/by/4.0/). 